\title{
Effects and optimization impact of wireless signal loss for subscribers in Lagos state
}

\author{
Akinyemi Lateef Adesola ${ }^{1,2}$, Shoewu Oluwagbemiga Omotayo ${ }^{2}$, Makanjuola Najeem Tunji², \\ Ajasa Abiodun Afis ${ }^{2}$, Folorunso Comfort Oluwaseyi², Raji Afis Omogbolahan ${ }^{2}$ \\ ${ }^{1}$ Department of Electrical Engineering, Faculty of Engineering and the Built environment, University of Cape Town, Western Cape, South Africa \\ ${ }^{2}$ Department of Electronic and Computer Engineering, Lagos State University, Epe Campus, Epe, Lagos, Nigeria
}

\section{Email address:}

Letua034@yahoo.com (L. A. Akinyemi), engrshoewu@yahoo.com (O. O. Shoewu), tunjimakanjuola@yahoo.com (N. T. Makanjuola), ajasaaf@yahoo.com (A. A.Ajasa), comfortobolajoko@yahoo.com (C. O. Folorunso)

\section{To cite this article:}

Akinyemi Lateef Adesola, Shoewu Oluwagbemiga Omotayo, Makanjuola Najeem Tunji, Ajasa Abiodun Afis, Folorunso Comfort Oluwaseyi, Raji Afis Omogbolahan. Effects and Optimization Impact of Wireless Signal Loss for Subscribers in Lagos State. American Journal of Networks and Communications. Vol. 3, No. 5, 2014, pp. 63-72. doi: 10.11648/j.ajnc.20140305.11

\begin{abstract}
This paper presents the effects and optimization impact of wireless signal loss for subscribers in Lagos state, using $3 \mathrm{G}$ as a study. This paper is aimed at analyzing network coverage data obtained through drive testing on the investigated area to detect coverage holes or area with poor coverage. The collected data showed significantly where the problems were via pre drive test and analysis was performed to proffer solutions to identified problems. This was later confirmed with a post drive test. The Key Performance Indicators (KPI) which include Receive Signal Code Power(RSCP), Energy per chip to noise ratio(Ec/No), Speech Quality Index(SQI), User Equipment Transmit Power(UE Tx Power), Active Set number of members were analyzed and showed significant improvement after optimization where necessary. The RSCP coverage quality showed an appreciable improvement from $40 \%$ to over $76 \%$ of good coverage after optimization. Results after the optimization reveals that the Call Setup Success Rate increased from about $96 \%$ to about $98 \%$ and the Call Drop Rate reduced from $0.664 \%$ to $0.62 \%$ out of 940 and 493 total number of calls attempts made during the pre and post drive test respectively. Besides, areas with more than three active set which could result into pilot pollution were identified and corrected by adjusting of the parameter (tilt) of the antenna involved.
\end{abstract}

Keywords: Optimization, Signal Attenuation, Receive Signal Code power, User Equipment (UE), Speech Quality Index, UE Transmit Power, Active Set Number of Members

\section{Introduction}

Currently $3 \mathrm{G}$ is a common technology which adopts the Wideband Code Division Multiple Access (WCDMA) technique for data encoding but yet the signal losses still prevail. Although signal attenuation along transmitting media cannot be $100 \%$ avoided but can be drastically reduced to a tolerant minimum. However, signal attenuation not resulting from transmitting media still prevails and it affects the end users connected to it.

Gone are the days when analog telephones were in use, traffic were sent through transmission lines or communication cables (copper wires) and at certain range or distance repeaters are used to revive the transmitted signals. The use of repeaters is due to attenuated signals i.e. losses of signals along the transmission line, so they are used to amplify or to boost the attenuated signals. The improvement of technology delved into the digitizing of communication links which was later called $2 \mathrm{G}$ technology which uses the Time Division Multiple Access (TDMA) technology. Several base stations are used and signals are transmitted wirelessly from one point to another, but at certain times, there are signal losses which may be due to landslide, transmission path, topography, distance from the serving site, weather condition, antenna tilt, buildings, natural obstruction, etc. All of these may cause losses of signal or attenuation of signal at certain times.

\section{Literature Review}

The Code Division Multiple Access (CDMA) unlike the Time Division Multiple Access (TDMA) where everyone is 
given a time slot to talk at a constant frequency, the extended range of CDMA replaces the time based multiplexing with code-based multiplexing, it allocates for everyone to talk at the same time and constant frequency but it is similar to everyone saying a different language or uniquely communicating with different line of codes and all signal or traffic appears as jargons to anyone who intends to tap into the signal or fetch transmitted information without due permission.

After lot of improvement on the $2 \mathrm{G}$, then came the new technology called the mobile broadband revolution. This technology uses a frequency spectrum of $2100 \mathrm{MHz}$ and was called the $3 \mathrm{G}$. The $3 \mathrm{G}$ standard utilizes a new technology called the UMTS (Universal Mobile Telecommunications System) as its core network architecture. The 3G technology combines some aspect of $2 \mathrm{G}$ and new technologies and protocols for delivering significantly faster data rate.

It is based on the International Telecommunication Union (ITU) family of standards under the International Mobile Telecommunications-2000 (IMT-2000). The aim of IMT200 was to implement a global frequency band that would support a single, widespread wireless communication standard for all countries, to provide the framework for the definition of the $3 \mathrm{G}$ mobile system. Several radio access technologies have been accepted by ITU, which is either based on CDMA or TDMA technology $[1,3,6]$.

The 3rd Generation Partnership Project (3GPP) is an organization that has defined a mobile system that fulfills the IMT-2000 standard. This system is called Universal Mobile Telecommunications System (UMTS). ITU finally approved a family of five $3 \mathrm{G}$ standards which are part of the $3 \mathrm{G}$ frame work known as IMT2000 [7]. Among the standards are WCDMA, CDMA2000 and TD-SCDMA [3, 4].

\section{Methodology}

Data collection was done through drive test with the used of data collection software. Drive Testing is a method of measuring and assessing the coverage, capacity and Quality of Service (QoS) of a mobile radio network and this is done by using drive test tools to take measurement of radio network performance around a given location with the use of a car [9]. TEMS is a wireless drive test optimization and troubleshooting software tool. It is a leading tool for wireless network troubleshooting, verification, and maintenance of wireless networks [8].TEMS software version 10.0.4 was used for data collection alongside other tools which include: test phone, Global Positioning System (GPS) dongle, connector cable, power inverter, and laptop MapInfo and Excel 2007 Package were used for the data analysis.

The process of collecting data was in two phases; the predrive, that is the drive done before optimization, which started on the 17th of July 2013 during the day starting from about 9:00 AM to about 5:00 PM in the evening. The predrive test ended on the 22nd of July 2013 while the post drive test, that is the drive done after optimization, started on the 19th November 2013 and ended on the 25th of November
2013. The period between the pre drive and the post drive was used for optimization implementation.

The routes to be driven are loaded on the TEMS interface, this is a specially prepared file which strictly indicates the paths to be taken during the drive. It should be noted that the route is specially drawn to cover the three sectors of most of the sites in the cluster.

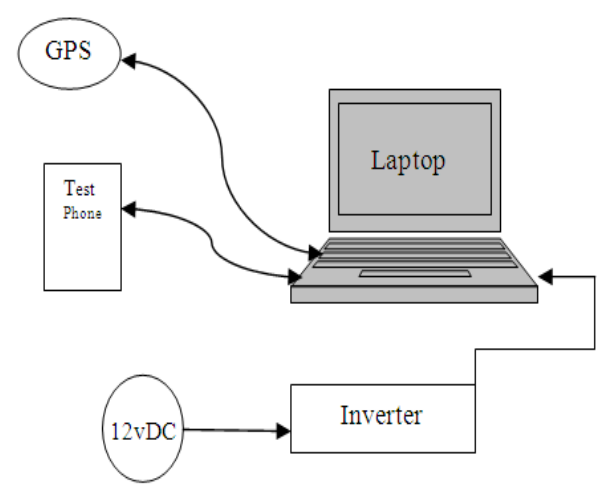

Figure 1. Experimental setup of the drive test tools.

\subsection{Area of Study}

The region of study is a densely populated area, Ikeja, Lagos State, Nigeria. The network coverage holes were detected and optimization techniques were deployed to correct them. This area and others neighbouring regions such as Magodo, Ojota, Agege and Egbeda can be seen on the map shown in Figure 2 below.

\section{Results and Discussion}

The results of the drive test obtained are in two phases as stated earlier. The first phase is to analyse the drive done before optimization. This will help identifying the problems and to know the optimization technique(s) to use. Next is to recommend optimization methods to be deployed. The second phase is to verify by doing a post drive test, if the optimization done has corrected what it was intended. The picture of the whole routes driven is shown in Figure 3.

\subsection{Key Performance Index Parameters (KPI)}

The KPI parameters that will be analysed are the RSCP, Ec/No, UE Tx Power, Active Set (AS) number of members, SQI and BLER (Block Error rate) during the analysis as well and its analysis will be shown graphically.

After analysing the pre drive test data, there was poor coverage around ikeja, magodo, ojota just to mention a few, which was due to poor RSCP level and EclNo. Similarly, there were high counts for the transmit power from the user equipment which need to be brought to a stable range, less than zero. From the analysis as well, it was observed and recorded some areas with more than three active sets which may eventually lead to pilot pollution. Hence, the following solutions were proffered via optimization techniques which include [7]:

- Increase of antenna Tx power 
- Swapped sectors correction

- Antenna tilts adjustment which includes electrical tilt and mechanical tilt.

- $\quad$ New site proposal
- Changes in antenna direction

- Radio Frequency parameter planning for new and existing sites which include reallocation of new scrambling codes.

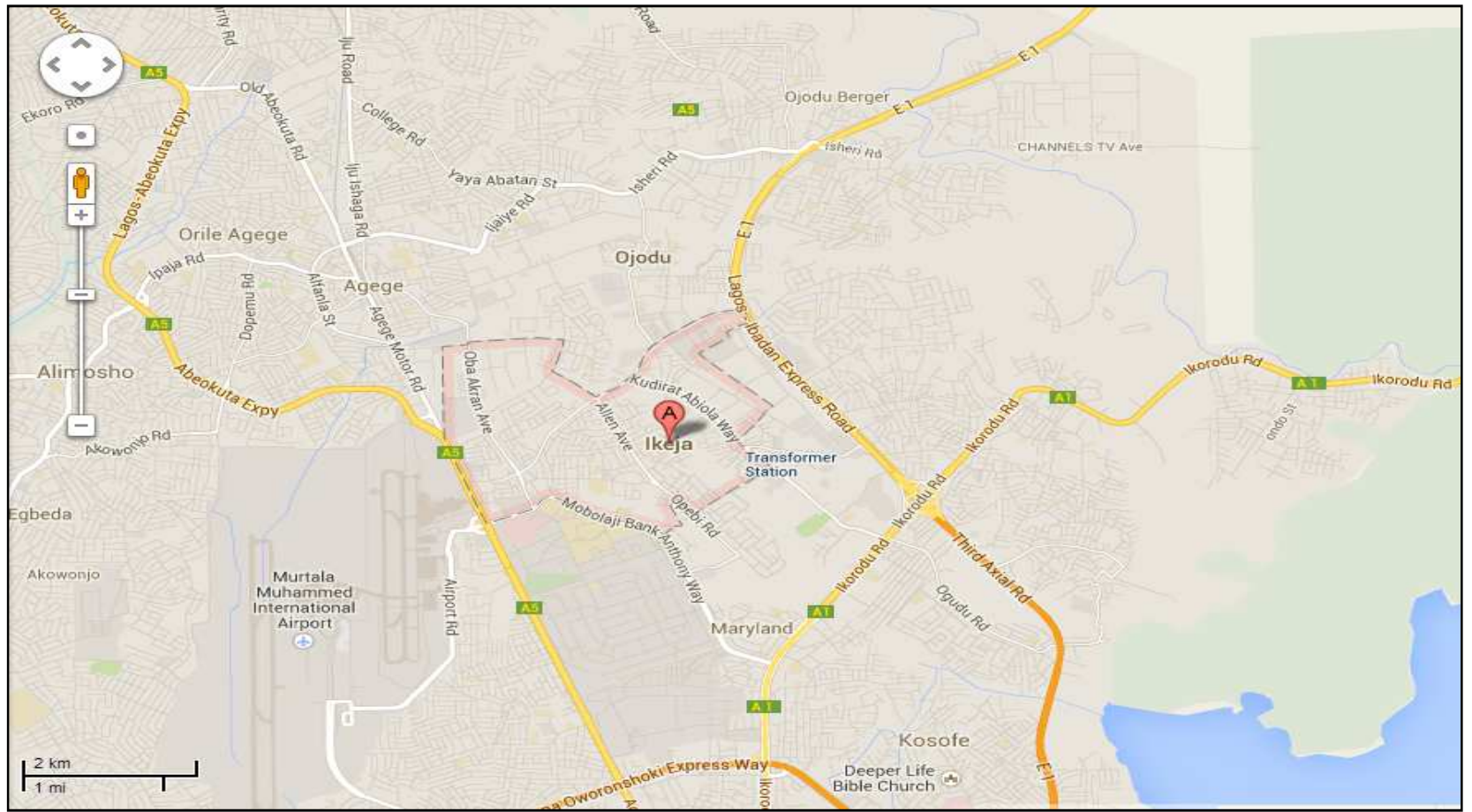

Figure 2. Google Map of areas of study, Ikeja, Magodo,Ojota etc

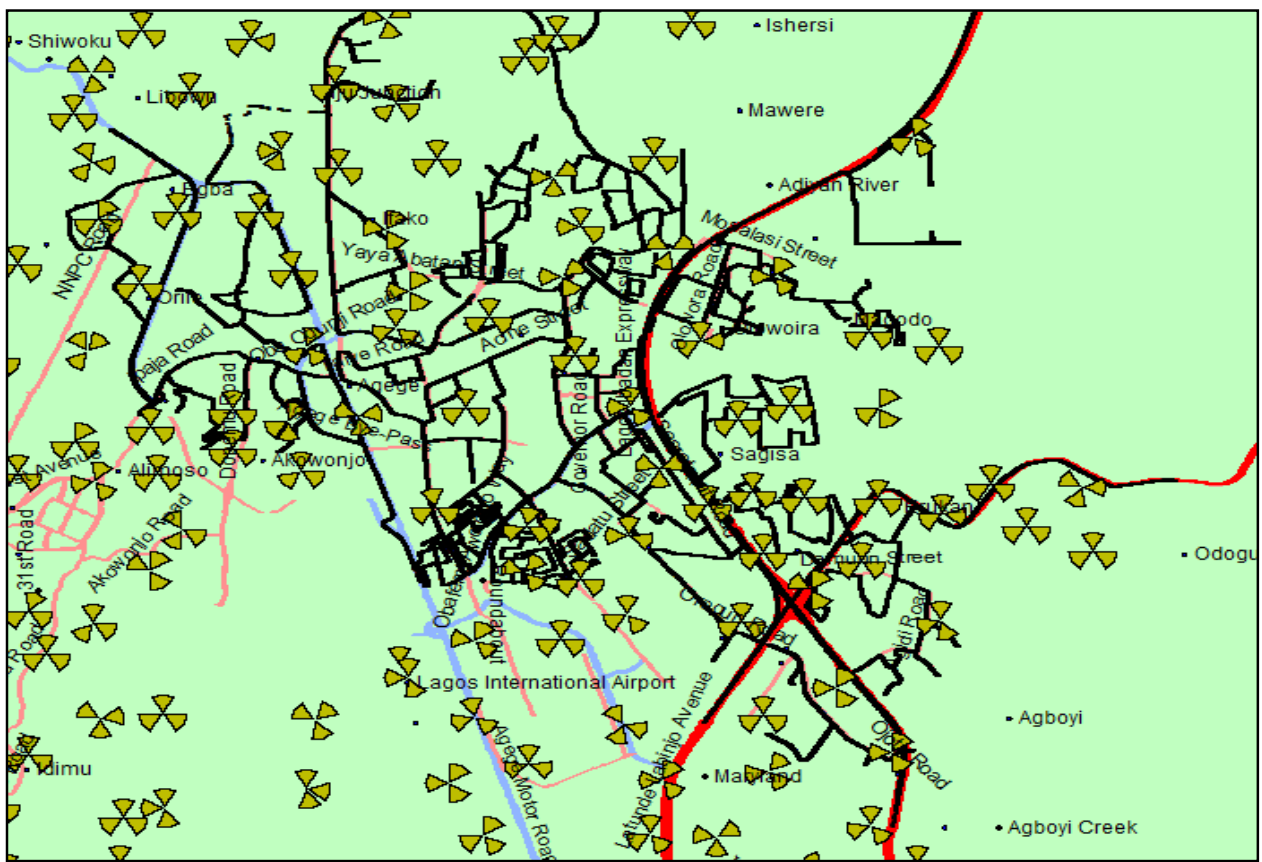

Figure 3. Drive test routes loaded on TEMS interface.

In this paper, the KPI parameters with significant improvement which have enhanced the network performance of the area of study will be graphically shown and comparative plots will also be used to further the explanation. These parameters include the RSCP, UE Tx Power, AS No of members, and the Speech Quality Index. Other parameters such as Ec $\backslash$ No and BLER also were improved during the post drive.

For better understanding of the level of improvement measurement, a legend is used for each of the KPI parameters in these areas of study and it includes: 


\subsubsection{Receive Signal Code Power (RSCP) at Ikeja}

Table 1. RSCP Legend used at Ikeja

\begin{tabular}{lll}
\hline Rscp Ranges & Colour & Remark \\
\hline-65 to -15 & Blue & Excellent \\
-75 to -65 & Light Green & Very good coverage \\
-85 to -75 & Deep Green & Good coverage \\
-95 to -85 & Yellow & Poor coverage \\
-125 to -95 & Red & Very bad coverage \\
\hline
\end{tabular}

\subsubsection{Speech Quality Index (SQI) at Ikeja}

Table 2. SQI Legend used at Ikeja

\begin{tabular}{lll}
\hline SQI Ranges & Colour & Remark \\
\hline 4 to 20 & Dark Blue & Excellent \\
3 to 4 & Light Blue & Very good quality \\
2 to 3 & Green & Good quality \\
1 to 2 & Yellow & Poor quality \\
Below 1 & Red & Bad quality \\
\hline
\end{tabular}

\subsubsection{UE TX Power at Ikeja}

Table 3. UE TX Power Legend used at Ikeja

\begin{tabular}{lll}
\hline Ue Tx Power Ranges & Colour & Remark \\
\hline 0 to 44 & Blue & Excellent \\
-8 to 0 & Deep Green & Very good quality \\
-34 to -8 & Yellow & Good quality \\
-60 to -34 & Red & Poor quality \\
\hline
\end{tabular}

\subsubsection{Ec/No at Ikeja}

Table 4. Ec/No Legend used at Ikeja

\begin{tabular}{lll}
\hline Ec/No Ranges & Colour & Remark \\
\hline-8 to 0 & Blue & Excellent \\
-10 to -8 & Light Green & Very good coverage \\
-12 to -10 & Deep Green & Good coverage \\
-14 to -12 & Yellow & Poor coverage \\
-24 to -14 & Red & Very bad coverage \\
\hline
\end{tabular}

\subsubsection{Block Error Rate (BLER) at Ikeja}

Table 5. BLER Legend used at Ikeja

\begin{tabular}{lll}
\hline BLER Ranges & Colour & Remark \\
\hline 20 to 200 & Red & Very bad coverage \\
15 to 20 & Yellow & Poor coverage \\
10 to 15 & Light Green & Good coverage \\
5 to 10 & Deep Green & Very good coverage \\
0 to 5 & Blue & Excellent \\
\hline
\end{tabular}

The AS number of members is a count that explains the number of active set present or available for mobile equipment at a particular area or place.

Prior and after the optimization techniques deployment, during the analysis of the drive test, some of the results were plotted and tabulated as shown below:

\subsection{Pre Drive Test Receive Signal Code Power (RSCP) Plot}

Using the afore stated legend, it can be clearly deduced that the coverage level of the network in these areas is generally poor owing to a poor and bad coverage counts amounting to over 1.5 million which is about over $60 \%$ of the whole coverage plots. This means that areas with good coverage are only about $40 \%$ less than of the whole area. That is sum of range count from -15 to $-85(\mathrm{dbm})$

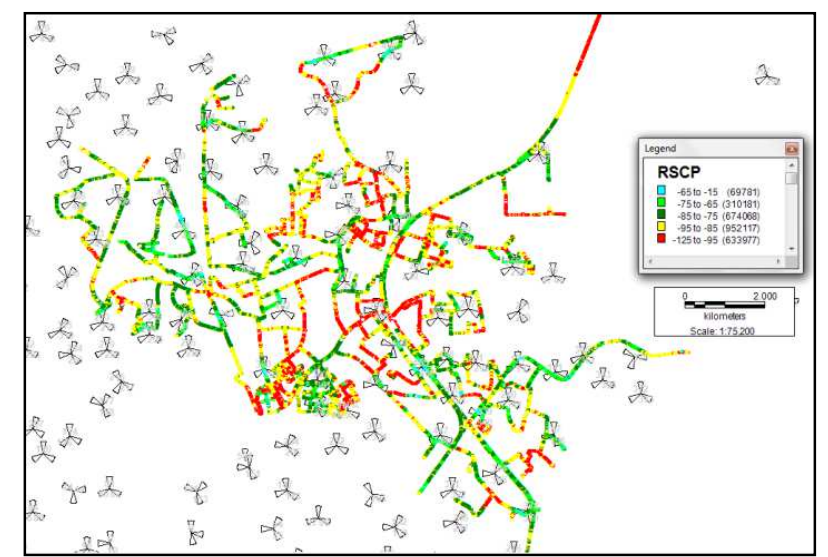

Figure 4. RSCP pre drive test plot in ikeja, magodo, Ojota

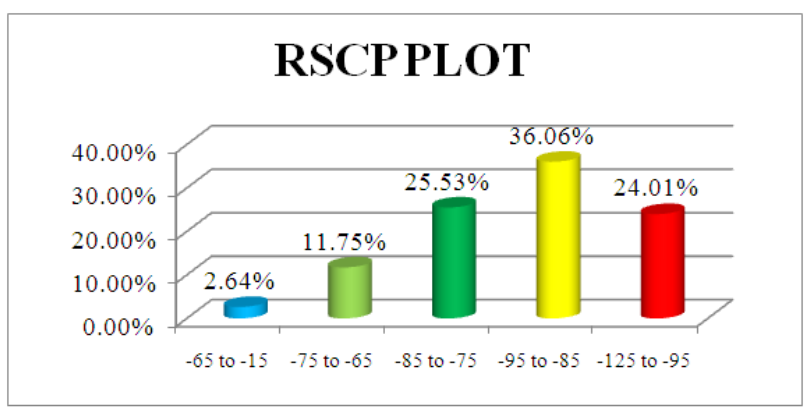

Figure 5. Pre drive test RSCP bar chart in ikeja, magodo, Ojota

\subsection{Post Drive Test Receive Signal Code Power (RSCP) Plot}

There is significant improvement in the level of coverage quality and distance. A total of about $76.14 \%$ of good coverage(sum of counts ranging from -15 to -85) was recorded leaving us with about less than $22 \%$ of poor coverage areas and less than $2.5 \%$ with areas associated with bad coverage counts. This is shown in Figure 7.

The reason for some poor coverage areas is due to the fact that some of the proposed sites are not yet on air and as soon as they are on air, some of these poor coverage counts in these areas will be reduced. 


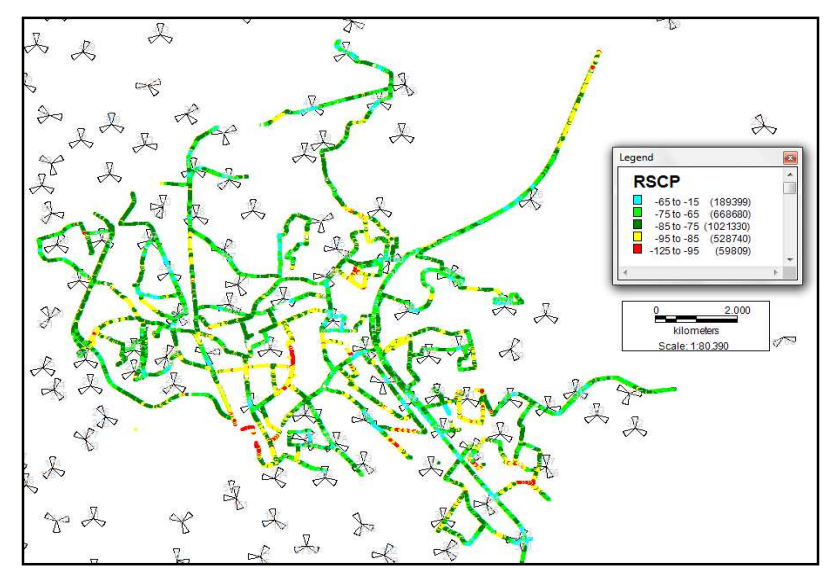

Figure 6. RSCP post drive test plot in ikeja, magodo, Ojota

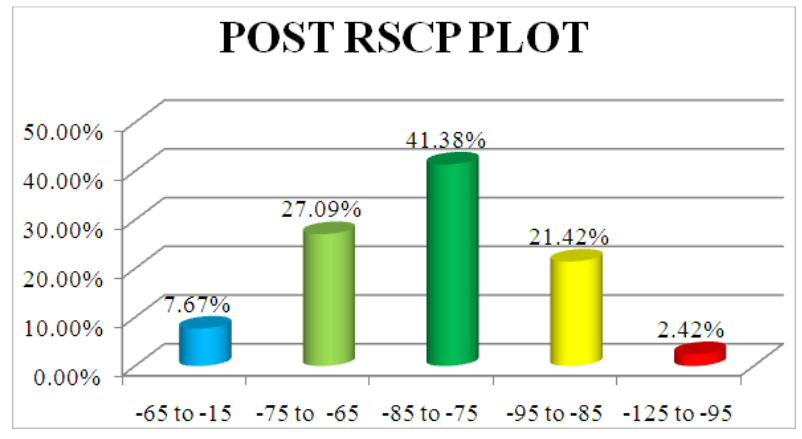

Figure 7. Post drive test RSCP bar chart in ikeja, magodo, Ojota

\subsection{Pre Drive Test Speech Quality Index (SQI) Plot}

As the name depicts, it gives a measure of the quality of speech and this is measured in the dedicated mode of the test phone. During the pre drive test, calls of 60 secs duration were made with an interval of $5 \mathrm{sec}$ to measure the SQI of these areas. This can be shown below.

A total of $66.96 \%$ of the areas had fairly good speech quality index (sum of counts ranging from 3 to 20). It can be seen from the plot that about $33 \%$ of the covered area had bad speech quality index counts (sum of counts below 2). During our findings, most of these problems were due to areas with too much traffic on the site.

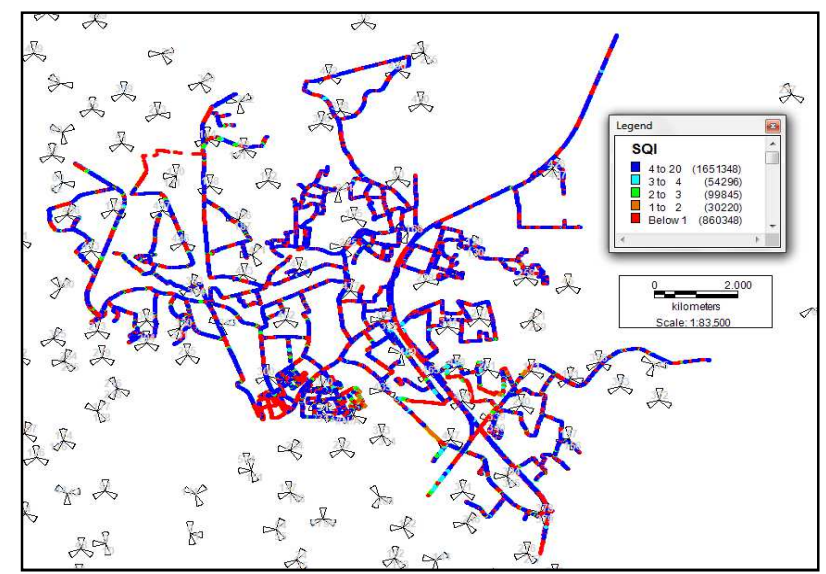

Figure 8. SQI pre drive test plot in ikeja, magodo, Ojota

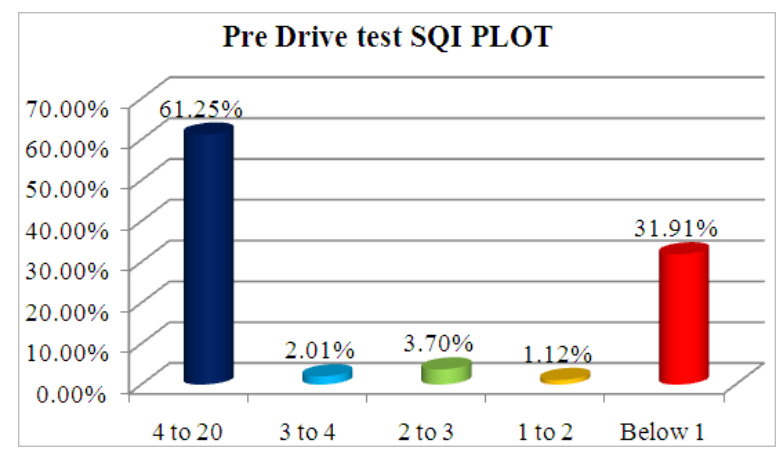

Figure 9. Pre drive test SQI bar chart

\subsection{Post Drive Test Speech Quality Index (SQI) Plot}

A total of $77.36 \%$ of the whole coverage area had remarkable SQI counts (sum of counts ranging from 3 to 20) and only about $23 \%$ less than the covered areas had bad SQI (sum of counts below 2), Similarly, this can be improved if the proposed sites are on air. This will enhance coverage quality and thus SQI will be improved.

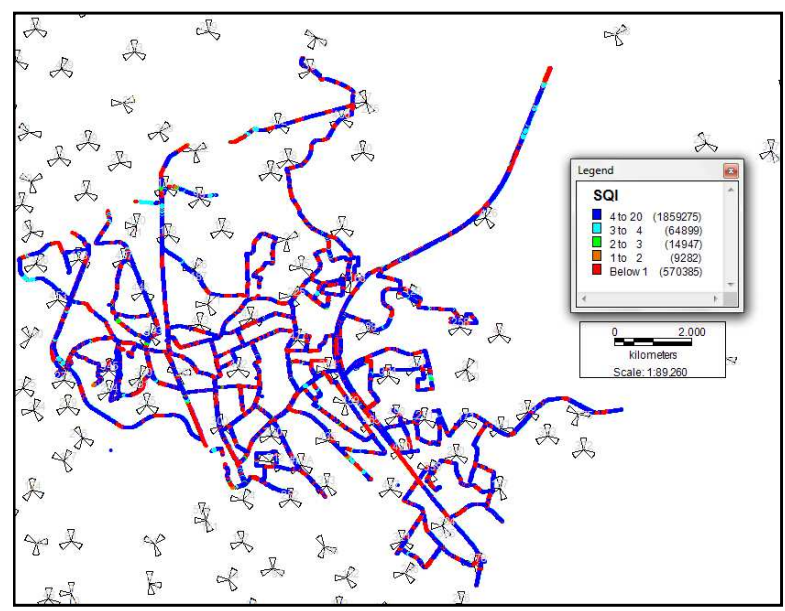

Figure 10. SQI post drive test plot in ikeja, magodo, Ojota etc

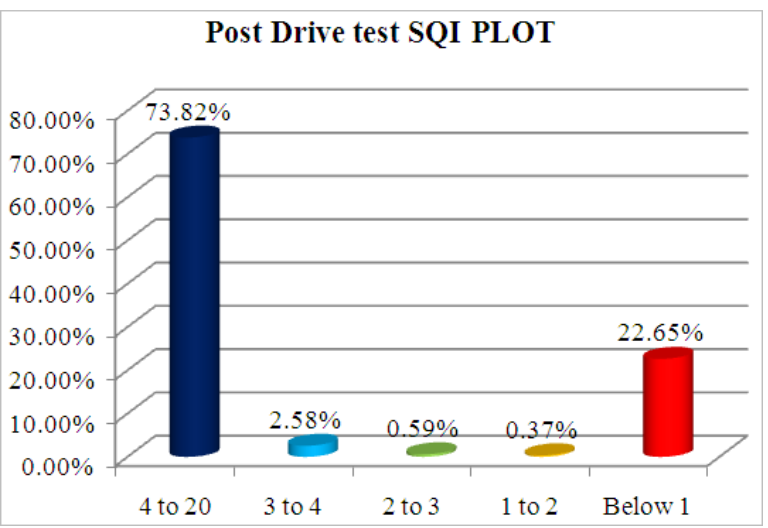

Figure 11. Post drive test SQI bar chart

\subsection{Pre Drive Tests UE Tx Power Plot}

The UE Tx Power plot simply gives the range of the transmit power of our mobile devices. If the signal coverage 
is good and close to a base station, it is expected that our mobile device uses the least amount of its power to communicate with the base station, conversely, if signal coverage is poor or bad our devices will tend to do more work to communicate with the base station. This can also occur if we devices are far away from the base station because naturally signal fading occurs with increase in distance.

Graphically, this can be shown below:

It can be carefully observed that areas with very high transmit power are places with poor coverage values.

This simply means that improving our coverage quality will positively affect or rather improve the Tx power of user equipment by reducing the amount of transmit power from the mobile devices. One of the advantages of this is that it will increase the battery life of our mobile device.

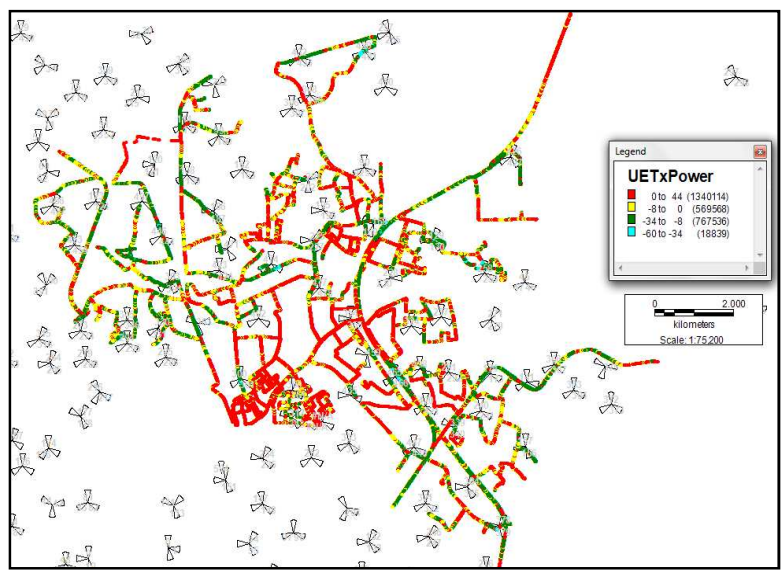

Figure 12. UE Tx Power pre drive test plot in ikeja, magodo, Ojota

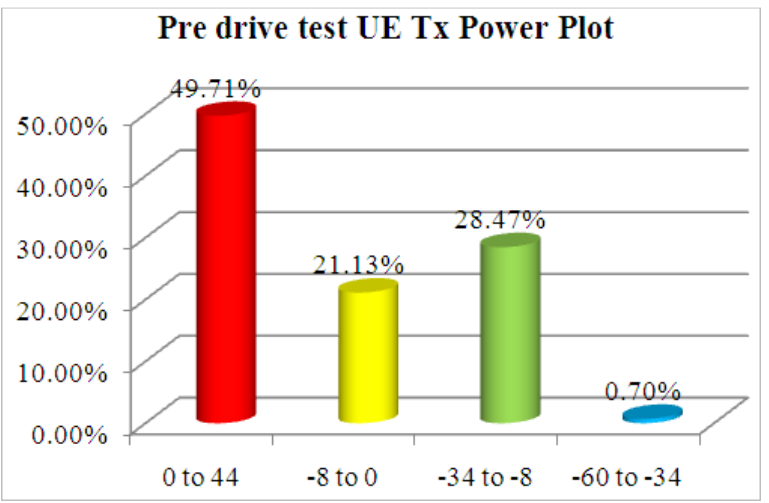

Figure 13. Pre drive test UE Tx Power bar chart

\subsection{Post Drive Test UE Tx Power Plot}

As it can be seen from the above plots, the amount of transmit power from our mobile equipment most especially our mobile phones had been drastically reduced. About $67 \%$ of the coverage areas have the transmit power of their user equipments reduced (sum of counts ranging from -34 to -8 ). About 33\% (sum of counts ranging from -8 to 44 ) of the area still has high transmit power from their equipment and this will be rectified if the newly proposed sites are made to be available on air.

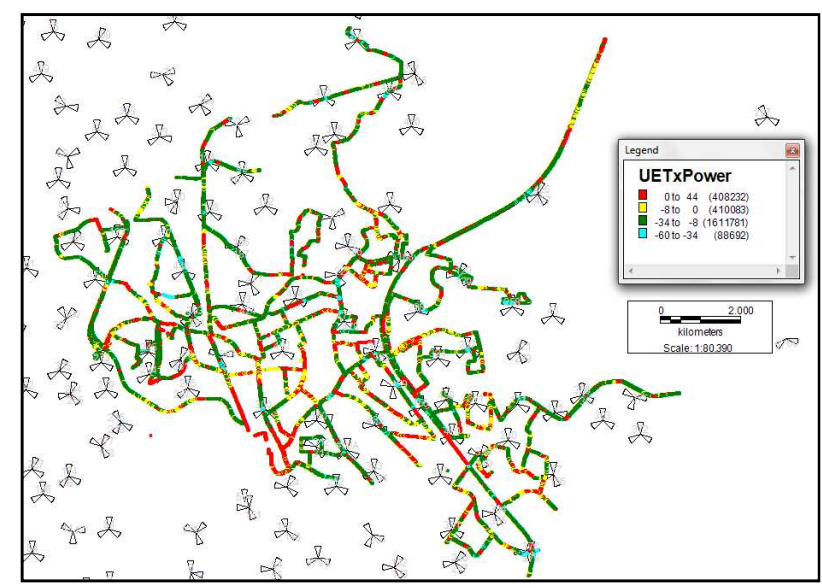

Figure 14. UE Tx Power post drive test plot in ikeja, magodo, Ojota

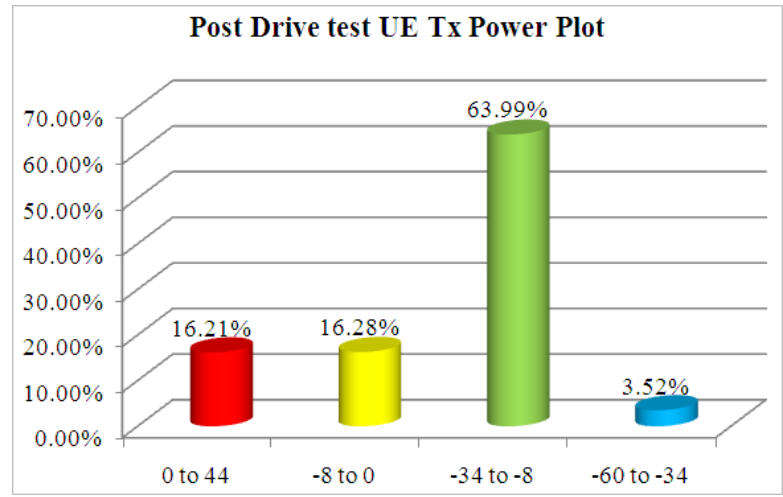

Figure 15. Post drive test UE TX Power bar chart

\subsection{Pre Drive Test AS Number of Members Plot}

As mentioned explained earlier on, it gives a total count of places where there were more than three Active Sets for a mobile device. This can be shown in the plot below.

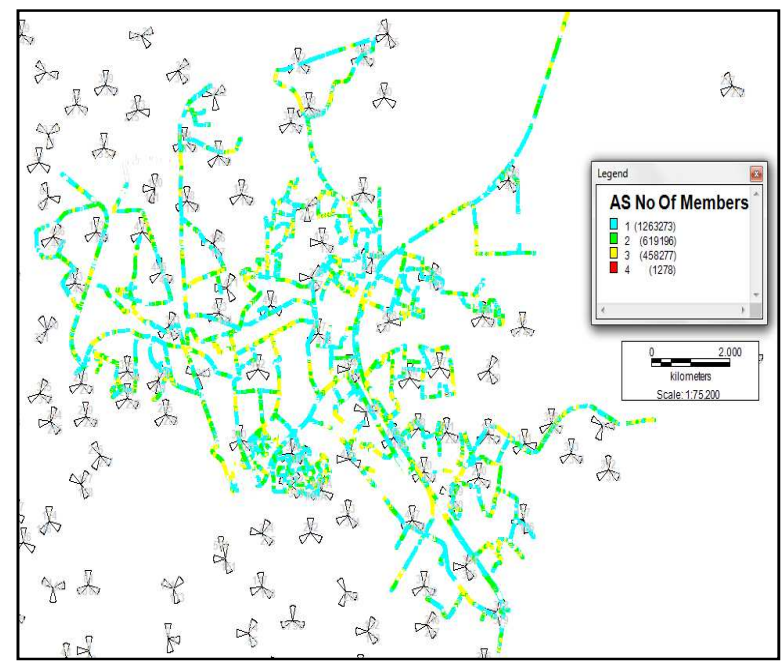

Figure 16. AS number of members pre drive test plot in ikeja, magodo, Ojota 


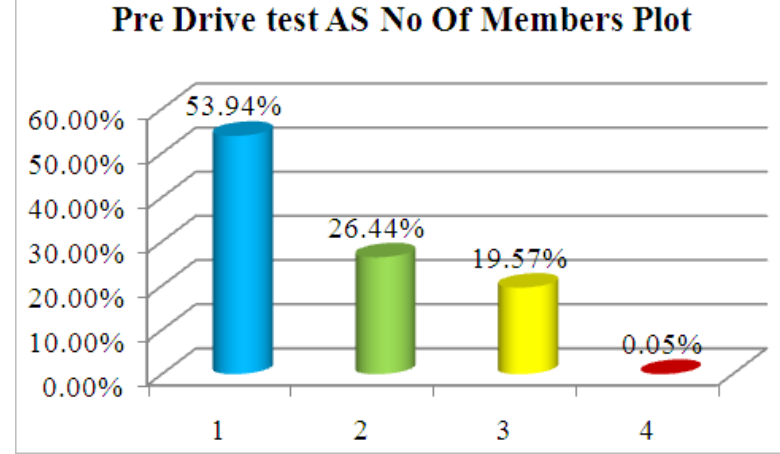

Figure 17. Pre drive test AS number of members' bar chart

Although, the count is very low, less than $1 \%$, but it was encountered that more than three active sets were recorded and this could result into pilot pollution.

After the post drive test, upon analysis to affirm that the optimization techniques deployed were effective and thus will make end users benefit reasonably and, the KPI parameter measured will be re-plotted to show the difference.

\subsection{Post Drive Test AS number of Members Plot}

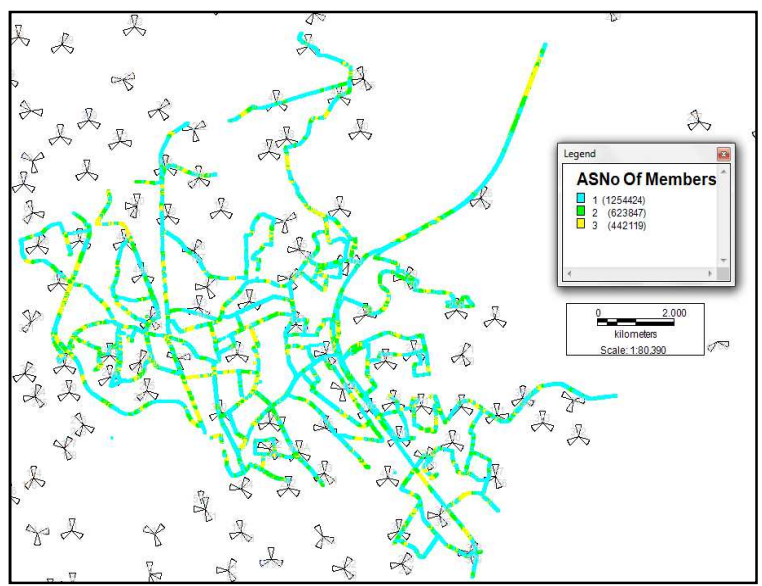

Figure 18. AS number of members post drive test plot in ikeja, magodo, Ojota

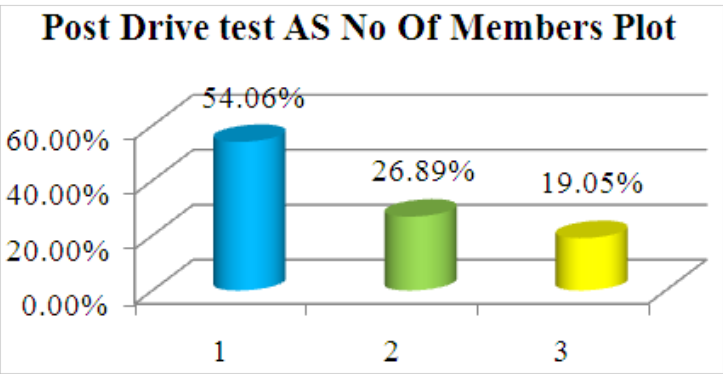

Figure 19. Post drive test AS number of members' bar chart

After post drive analysis, there was no record of more than three active set in the active set list of our mobile device. This had been eradicated by antenna direction adjustment and antennas transmit power reduction and also declaring a dominant server.

\subsection{Pre Drive Test Ec/No Plot}

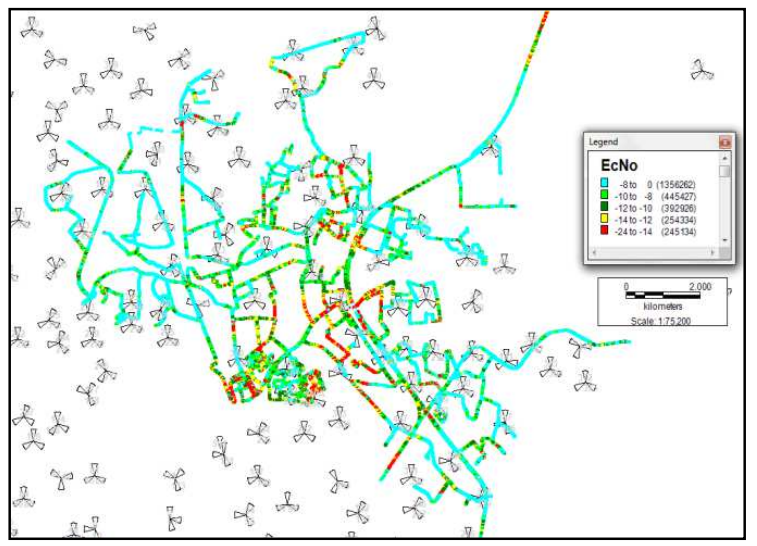

Figure 20. Ec/No Pre drive test plot in ikeja, magodo, Ojota

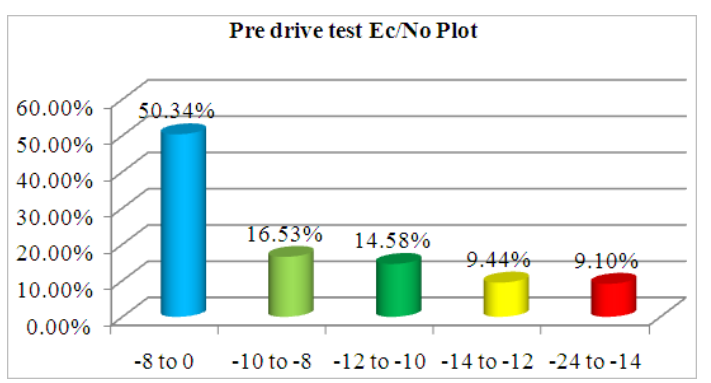

Figure 21. Ec/No Pre drive test bar chart

\subsection{Post Drive Test Ec/No Plot}

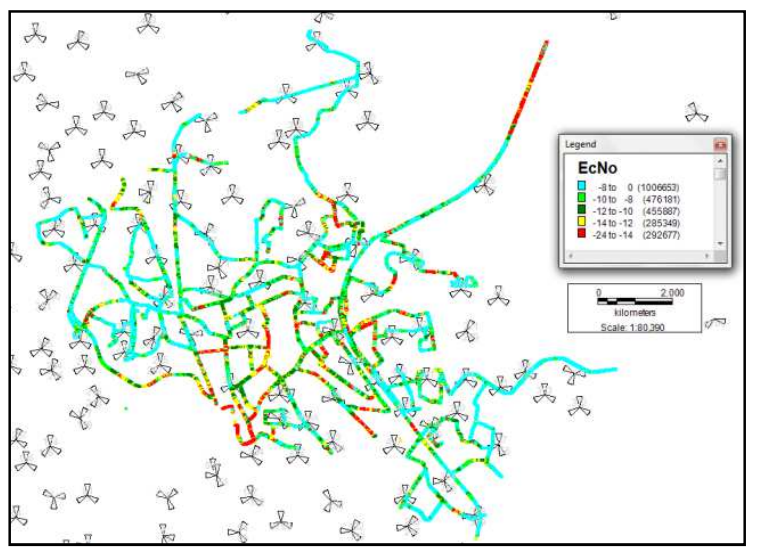

Figure 22. Ec/No post drive test plot in ikeja, magodo, Ojota

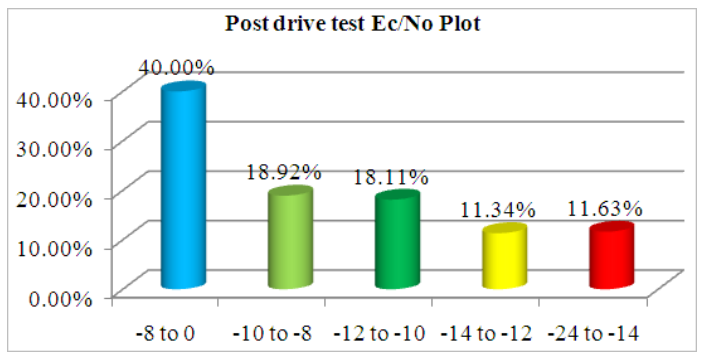

Figure 23. Ec/No Post drive test bar chart

During the pre drive, network counts for Ec\No were reasonably good except for places with poor Ec\No values 
which to a reasonable extent were corrected. Graphically, the counts are similar at both levels except for the ranges -8 to 0 . What accounted for this variance is that some places in Ikeja were not driven in the post drive which would have added to the good count of Ec\No value. The reason for not covering these places was due to car traffic and since other places with problems are to be covered those, places can be driven during other periods of optimization.

Also if the proposed sites are on air, the Ec/No quality will be improved in the areas with poor Ec/No values.

\subsection{Pre Drive Test BLER Plot}

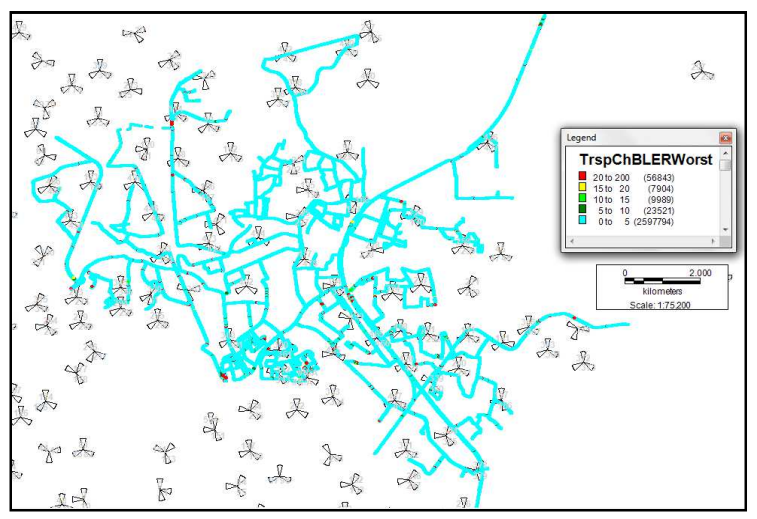

Figure 24. BLER Pre drive test plot in ikeja, magodo, Ojota

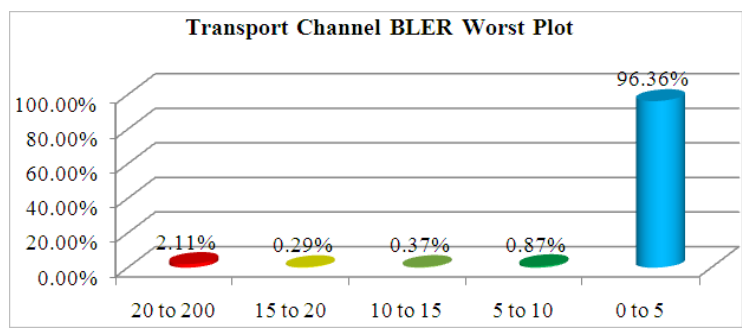

Figure 25. BLER Pre drive test bar chart

During the pre drive, the BLER showed a good coverage and it does not require any optimization technique. Graphically, the two plots can be seen as approximately the same that is having nearly the same counts.

\subsection{Post Drive Test BLER Plot}

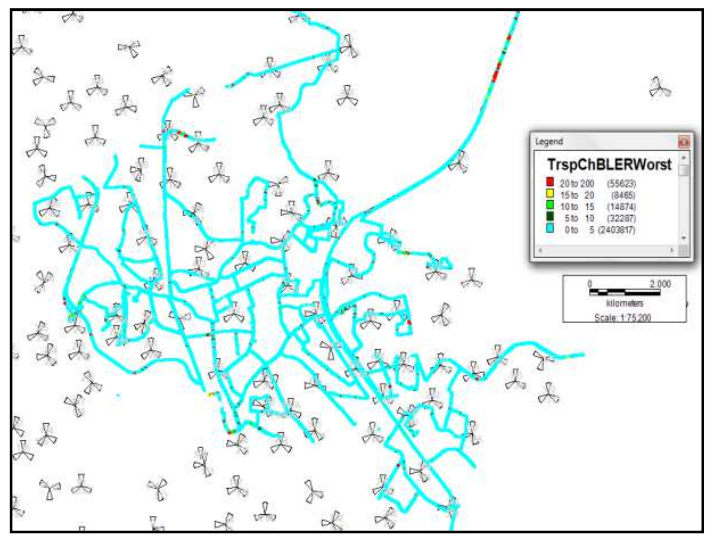

Figure 26. BLER Post drive test plot in ikeja, magodo, Ojota

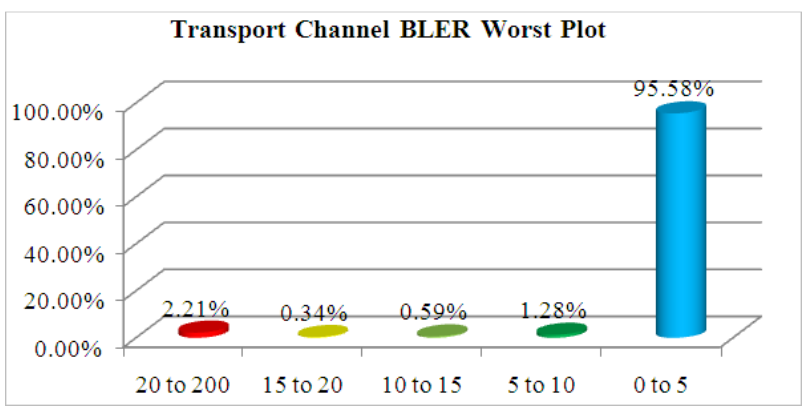

Figure 27. BLER Post drive test bar chart

\section{Comparative Analysis of KPI Parameters}

It was compared graphically that results obtained during the pre drive and post drive test, to see the level of improvements achieved.

\subsubsection{Comparative Receive Signal Code Power (RSCP) Plot}

Below gives the table for its comparison.

Table 6. Pre and Post drive test of RSCP Data counts.

\begin{tabular}{lllll}
\hline Rscp Ranges & $\begin{array}{l}\text { Pre-Drive } \\
\text { Counts }\end{array}$ & $\begin{array}{l}\text { Counts } \\
\text { In \% }\end{array}$ & $\begin{array}{l}\text { Post-Drive } \\
\text { Counts }\end{array}$ & $\begin{array}{l}\text { Counts } \\
\text { in \% }\end{array}$ \\
\hline-65 to -15 & 69781 & $2.64 \%$ & 189399 & $7.67 \%$ \\
-75 to -65 & 310181 & $11.75 \%$ & 668680 & $27.09 \%$ \\
-85 to -75 & 674068 & $25.53 \%$ & 1021330 & $41.38 \%$ \\
-95 to -85 & 952117 & $36.06 \%$ & 528740 & $21.42 \%$ \\
-125 to -95 & 633977 & $24.01 \%$ & 59809 & $2.42 \%$ \\
\hline
\end{tabular}

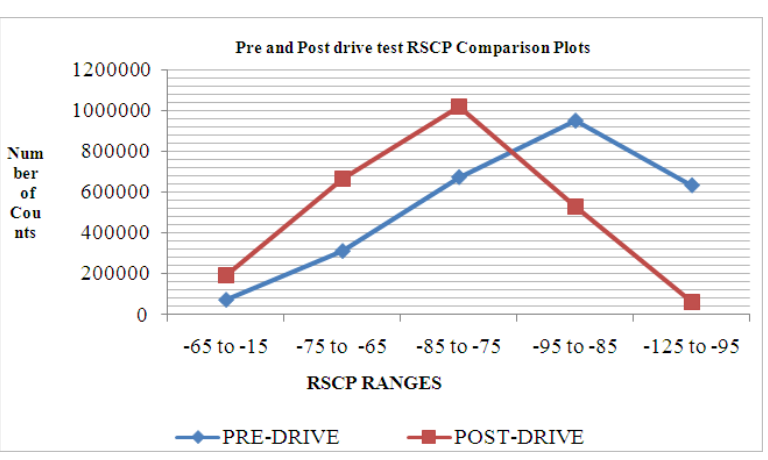

Figure 28. Pre and Post drive test RSCP comparison line graph

\subsubsection{Comparative Speech Quality Index (SQI) Plot}

Table 7. Pre and Post drive test for SQI Data counts.

\begin{tabular}{lllll}
\hline $\begin{array}{l}\text { SQI } \\
\text { Ranges }\end{array}$ & $\begin{array}{l}\text { Pre-Drive } \\
\text { Counts }\end{array}$ & $\begin{array}{l}\text { Counts } \\
\text { In \% }\end{array}$ & $\begin{array}{l}\text { Post-Drive } \\
\text { Counts }\end{array}$ & $\begin{array}{l}\text { Counts } \\
\text { In \% }\end{array}$ \\
\hline 4 to 20 & 1651348 & $61.25 \%$ & 1859275 & $73.82 \%$ \\
3 to 4 & 54296 & $2.01 \%$ & 64899 & $2.58 \%$ \\
2 to 3 & 99845 & $3.70 \%$ & 14947 & $0.59 \%$ \\
1 to 2 & 30220 & $1.12 \%$ & 9282 & $0.37 \%$ \\
Below 1 & 860348 & $31.91 \%$ & 570385 & $22.65 \%$ \\
\hline
\end{tabular}




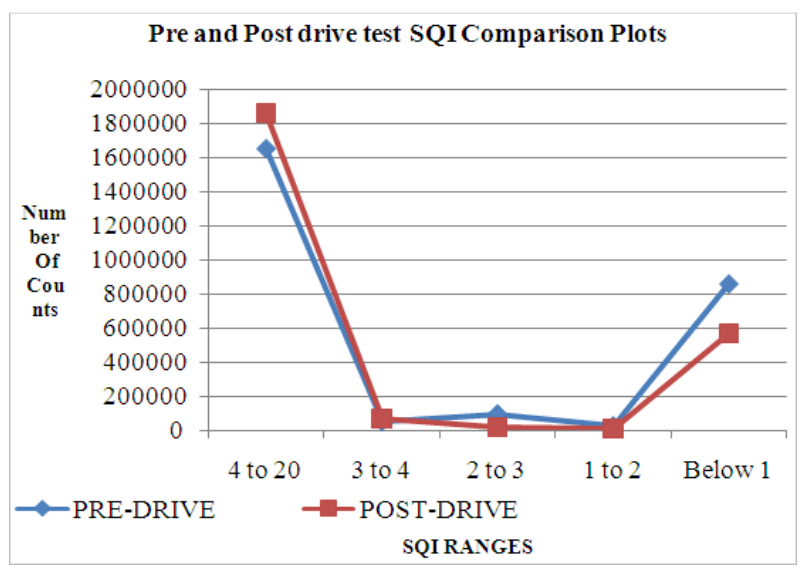

Figure 29. Pre and post drive test SQI comparison line graph

\subsubsection{Comparative UE Tx Power Plot}

Table 8. Pre and Post drive test for UE Tx Power Data counts.

\begin{tabular}{lllll}
\hline $\begin{array}{l}\text { Ue Tx Power } \\
\text { Ranges }\end{array}$ & $\begin{array}{l}\text { Pre-Drive } \\
\text { Counts }\end{array}$ & $\begin{array}{l}\text { Counts } \\
\text { In \% }\end{array}$ & $\begin{array}{l}\text { Post-Drive } \\
\text { Counts }\end{array}$ & $\begin{array}{l}\text { Counts } \\
\text { In \% }\end{array}$ \\
\hline 0 to 44 & 1340114 & $49.71 \%$ & 408230 & $16.21 \%$ \\
-8 to 0 & 569568 & $21.13 \%$ & 410083 & $16.28 \%$ \\
-34 to -8 & 767536 & $28.47 \%$ & 1611781 & $63.99 \%$ \\
-60 to -34 & 18839 & $0.70 \%$ & 88692 & $3.52 \%$ \\
\hline
\end{tabular}

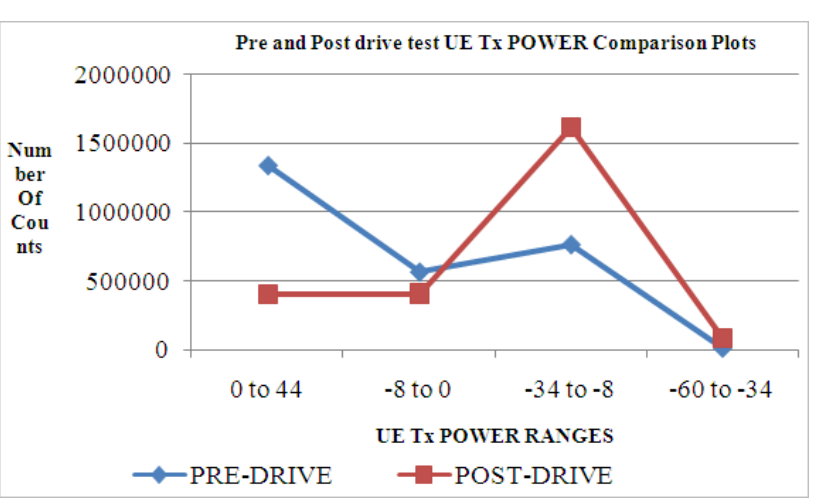

Figure 30. Pre and post UE Tx Power comparison line graph

\subsubsection{Comparative Ec/No Plot}

Table 9. Pre and Post drive test for Ec/No Data counts

\begin{tabular}{lllll}
\hline $\begin{array}{l}\text { Ec/No } \\
\text { Ranges }\end{array}$ & $\begin{array}{l}\text { Pre-Drive } \\
\text { Counts }\end{array}$ & $\begin{array}{l}\text { Counts } \\
\text { In \% }\end{array}$ & $\begin{array}{l}\text { Post-Drive } \\
\text { Counts }\end{array}$ & $\begin{array}{l}\text { Counts } \\
\text { In \% }\end{array}$ \\
\hline-8 to 0 & 1356262 & $50.34 \%$ & 1006653 & $40.00 \%$ \\
-10 to -8 & 445427 & $16.53 \%$ & 476181 & $18.92 \%$ \\
-12 to -10 & 392926 & $14.58 \%$ & 455887 & $18.11 \%$ \\
-14 to -12 & 254334 & $9.44 \%$ & 285349 & $11.34 \%$ \\
-24 to -14 & 245134 & $9.10 \%$ & 292677 & $11.63 \%$ \\
\hline
\end{tabular}

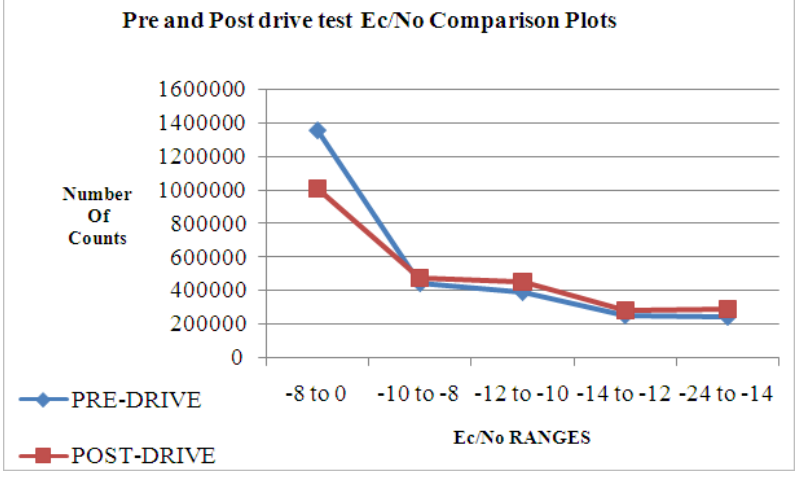

Figure 31. Pre and post Ec/No comparison line graph

\subsubsection{Comparative BLER Plot}

Table 10. Pre and Post drive test for BLER Data counts

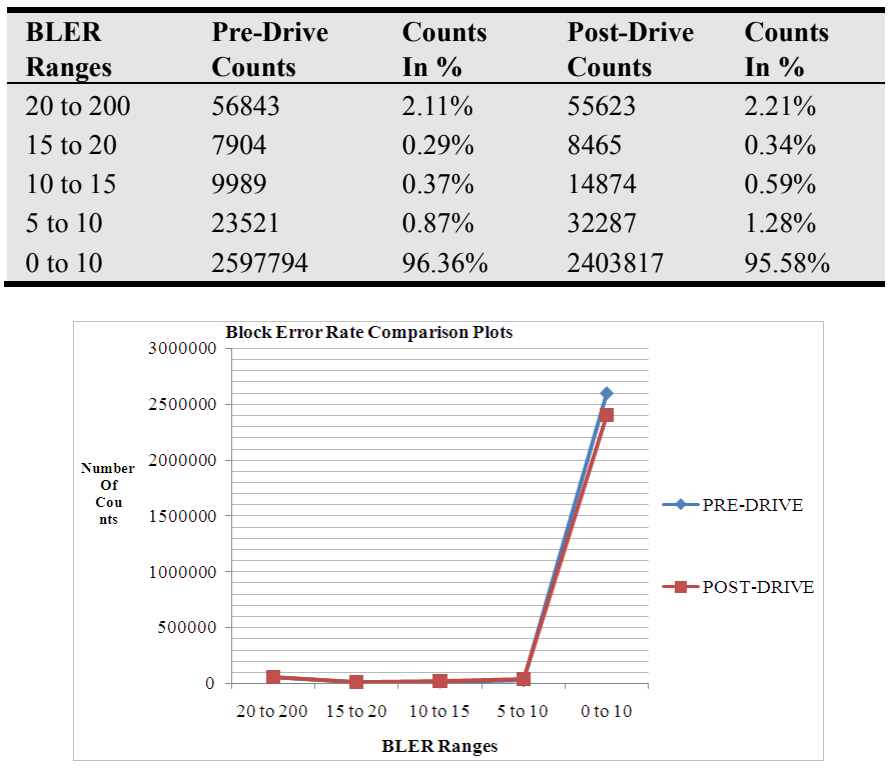

Figure 32. Pre and post BLER comparison line graph

\section{Call Analysis of the Study}

For the pre drive test analysis, this can be shown in the table below. The call setup success rate was obtained to be $96.06 \%$ with a call drop rate of $0.664 \%$.

Table 11. Pre drive test call analysis of the study.

\begin{tabular}{ll}
\hline Events & Quality \\
\hline Call Attempt & 940 \\
Call Setup Success & 903 \\
Call Setup Failure & 37 \\
Call Drop & 6 \\
CSSR & $96.06 \%$ \\
CDR & $0.664 \%$ \\
\hline
\end{tabular}

Upon analysis of the post drive, the Call Setup Success Rate (CSSR) increased from $96 \%$ to over $97.57 \%$ and as such reducing the Call Drop rate to about $0.6 \%$ unlike at an approximate value of $0.7 \%$ as was obtained for the pre drive. 
Table 12. Post drive test call analysis of the study

\begin{tabular}{ll}
\hline Events & Quality \\
\hline Call Attempt & 493 \\
Call Setup Success & 481 \\
Call Setup Failure & 12 \\
Call Drop & 3 \\
CSSR & $97.57 \%$ \\
CDR & $0.62 \%$ \\
\hline
\end{tabular}

Also, the reason why there are more call attempts in the pre drive is not far-fetched. This was because more routes were driven in the pre drive and there were traffic issues which amounted to more calls being initiated. Such routes were avoided in the post drive above.

\section{Conclusion}

It can be seen from the above analysis done that the need for a good network signal can be achieved if proper optimization is done at the right time. This is shown in the comparative analysis where the RSCP showed an improvement in the good counts range i.e. from -15 to -85 from about $39.9 \%$ to about $76 \%$, also the bad counts ranging from -85 to -125 reduced from $60 \%$ to $23.8 \%$ in the pre and post drive tests respectively. This is shown graphically in figure 28 above. Similarly, the SQI good count ranges from 1 to 20 showed improvement from $68 \%$ to $77.36 \%$. Also, the bad coverage counts reduced from $31.9 \%$ to $22.65 \%$ in the pre and post drive tests respectively. This is shown graphically in figure 29 above. All other KPI parameters showed significant improvement except for the Ec/No and BLER which showed approximately equal counts for the pre and post drive tests.

Optimization plays a vital role in the telecommunication industry and as such makes it a continuous process. Subscribers have the right to good and reliable network services and one of the ways of ensuring this is by properly monitoring all network sites, attend to customer complaints and deploy the most suitable optimization solution to such problems.

\section{Recommendations}

It is recommended that optimization which is a key solution to subscribers' problems should be made continuous, effective and implemented where necessary on time. Also, no coverage holes should be overlooked.

All newly implemented sites should be made available on air as soon as possible to improve network coverage areas and proper site monitoring should be done.

\section{Acknowledgements}

The authors gratefully acknowledged the cooperation of Etisalat Nigeria for the access granted to evaluate their network. Also, Omnicom Solutions Ltd for the test equipment provided.

\section{References}

[1] Ajay R. Mishra "Fundamental of Cellular Network planning and Optimization"2G/2.5G/3GEvolution_to 4G John Wiley and Sons Ltd.

[2] Dr. Abhijit Mitra; Department of Electronics and Communication Engineering, Indian Institute of Technology, India, November, 2009

[3] Guide to mobile Networks. telcoantennas.com.au/site

[4] Harri Holma and Antti Toskala, WCDMA for UMTS, Radio Access for Third Generation Mobile Communication, 2004

[5] Iana Siomina; Linkoping Studies in Science and TechnologyRadio Network Planning and Resource Optimization: Mathematical Models and Algorithms for UMTS, WLANs, and Ad Hoc Networks, 2007

[6] Sapna Shukla (et al), "Comparative Study of 1G, 2G, 3G and 4G”, Journal of Engineering, Computers \& Applied Sciences, April 2013

[7] Somer Goksel; Optimization and Log File Analysis in Gsm, January, 2003.

[8] Tems Investigation release notes, ascom, www.ascom.com/networktesting, 2011.

[9] http://en.wikipedia.org/wiki/Drive_testing 